\title{
Non-Zero/Non-Zero Alternations in Differential Object Marking
}

\author{
Stefan Keine \& Gereon Müller \\ Universität Leipzig
}

This paper proposes an analysis of alternations between two or more overt markers in differential object marking, which we claim to follow from impoverishment and harmonic alignment of markedness scales. The empirical evidence comes from Hindi, Mannheim German, Trumai and Cavineña.

\section{Theoretical Background}

\subsection{Harmonic Alignment}

Aissen $(1999,2003)$ proposes an analysis of differential argument encoding based on harmonic alignment as defined in (1) applied to the Hale/Silverstein hierarchies such as those in (2) (Hale (1972), Silverstein (1976)).

(1) Harmonic Alignment (Prince and Smolensky (2004))

Suppose given a binary dimension $\mathrm{D}_{1}$ with the scale $\mathrm{X}>\mathrm{Y}$ on its elements $\{\mathrm{X}, \mathrm{Y}\}$, and another dimension $\mathrm{D}_{2}$ with a scale $\mathrm{a}>\mathrm{b}>\ldots>\mathrm{z}$ on its elements $\{\mathrm{a}, \mathrm{b}, \ldots, \mathrm{z}\}$. The harmonic alignment of $\mathrm{D}_{1}$ and $\mathrm{D}_{2}$ is the pair of Harmony scales $\mathrm{H}_{X}, \mathrm{H}_{Y}$ :
a. $\quad \mathrm{H}_{X}: \mathrm{X} / \mathrm{a} \succ \mathrm{X} / \mathrm{b} \succ \ldots \succ \mathrm{X} / \mathrm{Z}$
b. $\quad \mathrm{H}_{Y}: \mathrm{Y} / \mathrm{Z} \succ \ldots \succ \mathrm{Y} / \mathrm{b} \succ \mathrm{Y} / \mathrm{a}$

The constraint alignment is the pair of constraint hierarchies $\mathrm{C}_{X}, \mathrm{C}_{Y}$ :
a. $\quad \mathrm{C}_{X}: * \mathrm{X} / \mathrm{z} \gg \ldots \gg * \mathrm{X} / \mathrm{b} \gg * \mathrm{X} / \mathrm{a}$
b. $\quad \mathrm{C}_{Y}: * \mathrm{Y} / \mathrm{a} \gg * \mathrm{Y} / \mathrm{b} \gg \ldots \gg * \mathrm{Y} / \mathrm{Z}$

(2) Scales
a. GF scale
Subject $>$ Object
b. Person scale
Local Person $\left(1^{\text {st }}, 2^{\text {nd }}\right)>3^{\text {rd }}$ person
c. Prominence scale
$\mathrm{X}>\mathrm{x}$ (discourse-prominent argument $>$ non-discourse-prominent argument)
d. Animacy scale
Human $>$ Animate $>$ Inanimate




\section{e. Definiteness scale \\ Pronoun $>$ Proper noun $>$ Definite $>$ Indefinite Specific $>$ Non-specific}

The resulting constraint alignments are then locally conjoined with the markedness constraint $* \emptyset_{C}($ Star-Zero(Case)), that penalizes case feature deletion, yielding a ranking of constraints that are violated if a DP does not have a case feature. Into this ranking another markedness constraint with the opposite effect is inserted into a language-specific position: ${ }^{*} \operatorname{STRUC}_{C}$ (Star-Structure(Case)), that is violated if a DP has a case feature. Depending on where $* \mathrm{STRUC}_{C}$ is inserted, case features are deleted for some arguments but not for others.

As a consequence, an argument can either have a case feature (if the relativized $* \emptyset_{C}$ outranks $* \mathrm{STRUC}_{C}$ ) or have no case at all (if $* \mathrm{STRUC}_{C}$ is ranked higher than the relativized $* \emptyset_{C}$ ). This implies that a DP either bears the standard case marker or no case marker at all. Our main proposal is that this yes/no alternation is empirically insufficient: There exist alternations between two (or more) overt markers that adhere to the same principles as the cases considered by Aissen, strongly suggesting a unified approach. Such an approach, however, is out of reach if the theory employed only accounts for yes/no alternations. The goal of the present article is to develop a theory of differential argument encoding that derives degrees of morphological marking. We will follow Aissen $(1999,2003)$ in employing harmonic alignment applied to markedness scales and local conjunction. Contrary to her analysis, we propose that differential argument encoding is a morphological phenomenon, not a syntactic one.

Some caveats are in order here: We assume here without discussion that Aissen's approach is basically valid and therefore will remain silent about possible alternatives (such as Stiebels (2002), Ortmann (2002), Trommer (2006)). Secondly, we will not argue against arguments that the whole enterprise is flawed (as raised in Carnie (2005), Haspelmath (2007)). Furthermore, the scales in (2) are assumed to be basic. Thus, their effects are not treated as epiphenomena of more general syntactic mechanisms (see Brown et al. (2004), Harbour (2008), Richards (2008) for such proposals). Lastly, we will simply assume that scale effects are indeed typologically real (cf. Bickel (2007), Bickel and Witzlack-Makarevich (2008) for a different view).

\subsection{Impoverishment}

The present proposal is embedded within the general grammatical architecture of Distributed Morphology (DM). Specifically, morphology applies post-syntactically and is realizational in nature. Abstract morpho-syntactic features are realized by morphological exponents, so-called vocabulary items. Vocabulary insertion is assumed conditioned by the subset principle and specificity: Only markers whose morpho-syntactic features constitute a subset of the syntactic head can be inserted. If more than one marker fulfills the subset principle the most specific one, i. e. the one comprising the most features, is chosen. On our proposal scale effects on case marking are brought about by impoverishment, an operation that deletes morpho-syntactic features before the exponents are inserted (see Bonet (1991), Halle and Marantz (1993, 1994), among many). Marker insertion that follows impoverishment applies to reduced feature matrices. Impoverishment thus leads to a more general marker than would otherwise be inserted (a 'retreat to the general case').

Since impoverishment leads to marker alternation, we propose that it provides the means to account for differential case marking, as this is essentially a phenomenon of 
marker alternation under certain conditions. As in standard DM, impoverishment postsyntactically deletes morpho-syntactic features. However, we suggest that it is not triggered by arbitrary rules but applies in order to satisfy high-ranked markedness constraints in an OT-style syntax-morphology mapping. The constraint ranking, and therefore impoverishment, is restricted by harmonic alignment of scales. It follows that impoverishment is functionally motivated and constrained.

\subsection{Iconicity}

Morphological impoverishment leads to marker alternation but nothing we have said so far implies that impoverishment leads to a smaller marker than the one standardly inserted. To derive the desired correlation between impoverishment and insertion of less phonological material, we assume the meta-grammatical principle of Iconicity.

\section{Iconicity Meta-Principle (Wiese (1999, 2004))}

Similarity of form implies similarity of function (within a certain domain, and unless there is evidence to the contrary).

Form here denotes the phonological properties of a marker; function, on the other hand, regards its morpho-syntactic features. Iconicity states that both are correlated: a marker's morpho-syntactic content matches its phonological complexity. To take an example, the zero marker is thus always the least specific marker. ${ }^{1}$ As seen above, impoverishment leads to insertion of markers with fewer morpho-syntactic features. By iconicity, this marker is also less complex phonologically, i. e. 'smaller'.

\section{Proposal}

The empirical basis for the present account is the observation that differential case marking is not necessarily a zero/non-zero alternation. Rather, it is a gradient phenomenon. Differential encoding is derived by impoverishment, which in turn is triggered by the interaction of faithfulness and markedness constraints. Their ranking is not arbitrary but derived in a systematic way by harmonic alignment of scales. Due to iconicity, impoverishment requires the insertion of a smaller marker. This marker can be, but need not be, the zero marker. The present proposal thus accommodates yes/no alternations but crucially provides a unified analysis with alternations between two overt markers.

\section{Case Studies}

\subsection{Object Marking in Hindi}

Let us consider some concrete examples to illustrate how the system works. First, we will look at a zero/non-zero marker alternation in Hindi. This phenomenon is then shown to obey the same principles as object marking in Mannheim German, which crucially is an alternation between two overt markers. The similarity notwithstanding, Aissen's (1999;

1 For the sake of exposition, we will simply assume here that morpho-syntactic complexity is determined on the basis of set cardinality. Of course, feature hierarchies might also be relevant here (as assumed e.g. in Wiese (1999), Lumsden (1992)). Phonological complexity is measured against a sonority scale. 
2003) approach can only account for the former effect, forcing one to treat the two effects as unrelated. In contrast, the present proposal derives both in a unified way.

In Hindi, objects of transitive verbs can bear either the case marker -ko or the zero marker (Mahajan (1990), Mohanan (1994), Woolford (2001), Stiebels (2002), Butt and King (2004), Anand and Nevins (2006), Keine (2007)). The latter appears if the object is non-definite and non-human; the former in all other cases. This is shown in (4) and (5).

\section{Specificity}

a. nadya $=$ ne gari cala-yi he

Nadya.F.SG=ERG car.F.SG.NOM drive-PERF.F.SG be.PRES.3SG

'Nadya has driven a car.'

b. nadya $=$ ne gari $=$ ko cala-ya he

Nadya.F.SG=ERG car.F.SG=ACC drive-PERF.M.SG be.PRES.3SG

'Nadya has driven the car.'

(Butt and King $(2004,161))$

Humanness

a. ilaa-ne ek bacce-ko / *baccaa ut ${ }^{h}$ aayaa

Ila-ERG one child-ACC / child.NOM lift/carry.PERF

'Ila lifted a child.'

b. ilaa-ne ek haar /*haar-ko ut ${ }^{h}$ aayaa

Ila-ERG one necklace.NOM / necklace-ACC lift.PERF

'Ila lifted a necklace.'

(Mohanan $(1994,79))$

Non-definite, non-human objects are least marked in terms of Hale/Silverstein hierarchies. This correlates with the lack of an overt marker, yielding a correlation between hierarchical and morphological markedness, which suggests an approach in terms of differential object marking. We will first outline the approach suggested in Keine (2007), which makes use of standard impoverishment, that is conditioned by arbitrarily stated features. This proposal is then compared to the one made here-namely, that the context of impoverishment ultimately results from harmonic alignment of scales.

Suppose that both -ko and the zero marker compete for insertion into the object. Conforming to iconicity, $-k o$ is more specific than the radically underspecified zero marker. Thus, the default exponent for the case assigned to the object is -ko. If, however, the object is canonical, impoverishment leads to an underspecified case feature, thereby bleeding insertion of $-k o$. Consequently, the more general zero marker is attached to the noun instead. This system is sketched in (6).
a. Case decomposition:
ACCUSATIVE: [+gov]
b. Vocabulary items:
$/$-ko/ $\leftrightarrow[+$ gov $]$
$/-\varnothing / \leftrightarrow[$ ]
c. Impoverishment rule:
$[+$ gov $] \rightarrow \emptyset /[$-specific, - human $]$

Note that the impoverishment rule in (6-c) does not derive the fact that hierarchical markedness is correlated with morphological markedness, as there is no principled reason why impoverishment should not apply to, say, highly marked objects only. In order to overcome this deficiency, we propose that the context of impoverishment is derived by harmonic alignment of scales. In what follows, we will thus assume the basic validity of the approach just outlined but dispense with the impoverishment rule in (6-c). 
Instead, we treat impoverishment as being triggered by optimality-theoretic constraints. Suppose the scales given in (7).
a. Animacy Scale
Human $>\overbrace{\text { Animate }>\text { Inanimate }}^{\text {Non-Human }}$
b. Definiteness Scale
... $>$ Specific $>$ Non-Specific
c. $\quad$ GF Scale Sc $^{2}$
Subject $>$ Object

Harmonic alignment of the GF scale with the animacy scale yields the harmony scales in (8-a). Independent harmonic alignment of the GF and the definiteness scales results in $(8-b)$.

$$
\begin{array}{lll}
\text { a. } & \text { (i) } & \text { Subj/Hum } \succ \text { Subj/NHum } \\
& \text { (ii) } \mathrm{Obj} / \mathrm{NHum} \succ \mathrm{Obj} / \mathrm{Hum}
\end{array}
$$
b. (i) $\quad$ Subj/Spec $\succ$ Subj/NSpec
(ii) $\mathrm{Obj} / \mathrm{NSpec} \succ \mathrm{Obj} / \mathrm{Spec}$

These harmony scales are then converted to the constraint alignments (9-a) and (9-b), respectively.

\section{Constraint Alignments}
a. (i) $*$ Subj/NHum $\gg *$ Subj/Hum
(ii) $*$ Obj/Hum $\gg *$ Obj/NHum
b. (i) $*$ Subj/HSpec $\gg *$ Subj/Spec
(ii) $*$ Obj/Spec $\gg *$ Obj/NSpec

Since our concern here is object marking, only (9-a-ii) and (9-b-ii) will be relevant here. As both humanness and definiteness are relevant for object case marking in Hindi, (9-a-ii) and (9-b-ii) need to be combined. This is achieved by (order-preserving) local conjunction, resulting in (10), which can be notationally simplified as in (11). This yields twodimensional argument encoding, as these constraints are specified for two properties of the objects (namely, definiteness and humanness).

\section{Local Conjunction}

a. $*$ Obj/Hum \& $*$ Obj/Spec $\gg * O b j / H u m ~ \& * O b j / N S p e c$

b. $*$ Obj/NHum \& $*$ Obj/Spec $\gg *$ Obj/NHum \& $*$ Obj/NSpec

\section{Notational Simplification of (10)}
a. $*$ Obj/Hum/Spec $\gg * O$ Obj/Hum/NSpec
b. $*$ Obj/NHum/Spec $\gg *$ Obj/NHum/NSpec

The effect of the constraints in (11) is to penalize objects with certain properties in themselves. Since the present proposal is only concerned with the case marking of objects, the

2 The basic GF scale leaves open how "subject" and "object" are to be defined. Throughout this paper, we will presuppose that grammatical functions are derivative notions-essentially, positions in phrase structure representations. On this view, we can assume that "subject" means "specifier of vP", and object "complement of V". Still, for the sake of exposition, in what follows we will mostly use the labels "subject" and "object" (rather than, say, "Spec(v)" and "Comp(V)"). 
constraints in (11) need to be relativized to case features. This is achieved by local conjunction with the faithfulness constraint MAX-CASE, which penalizes case feature deletion. MAX-CASE is thus equivalent to Aissen's $* \emptyset_{C}$. The result is given in (12).

\section{Local Conjunction with MAX-C(ASE)}

a. $*$ Obj/Hum/Spec \& MAX-C $\gg * O b j / H u m / N S p e c ~ \& ~ M A X-C$

b. $*$ Obj/NHum/Spec \& MAX-C $\gg * O b j / N H u m / N S p e c ~ \& ~ M A X-C$

Note that the ranking relations in (12) were not arbitrarily defined but arrived at by principled means. Harmonic alignment of scales and subsequent local conjunction thus lead to an inherent constraint ranking that cannot be altered. This ranking can also be depicted as in (13), where top-down order corresponds to fixed ranking relations.

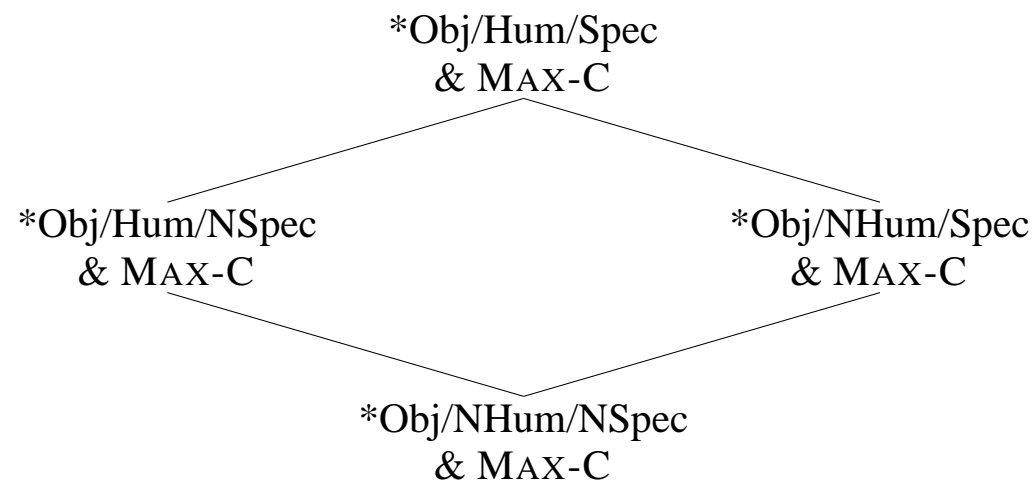

The constraints in (13) are only partially ranked: While *Obj/Hum/Spec \& MAX-C in-

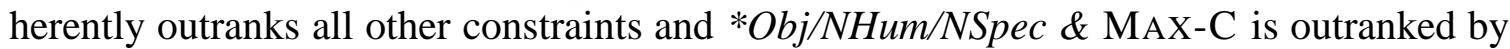
all other contraints, the relation between the constraints $* O b j / H u m / N S p e c ~ \& ~ M A X-C$ and $*$ Obj/NHum/Spec \& MAX-C is not intrinsically specified. Both, however, are ranked between the former two.

Note that all the constraints in (13) are faithfulness constraints that penalize case feature deletion for certain types of objects. In order to trigger case feature deletion, a markedness constraint against the presence of a given case feature is inserted into a languagespecific position. Depending on the point of insertion this markedness constraint may outrank some of the faithfulness constraints but not all. Contrary to Aissen (1999, 2003), we do not assume a general markedness constraint against case features. Rather, given decomposition of case into more primitive features, the markedness constraints at hand only penalize case subfeatures. This has the effect of only partial case feature deletion, leaving the other subfeatures intact. Deletion therefore does not necessarily lead to a total case reduction, opening up the possibility of a retreat to a more general - but still not most general - marker. A second effect is that there might exist more than one markedness constraint, resulting in several impoverishment steps. While not relevant for Hindi, this will turn out to be desirable for Trumai below. As for Hindi, the constraint * [+gov], which is violated if a DP bears the case feature [+gov], is inserted as in (14).

$$
\begin{aligned}
& \text { Final ranking } \\
& \left\{\begin{array}{l}
* \text { Obj/Hum/Spec \& MAX-C, } \\
* \text { Obj/Hum/NSpec \& MAX-C, } \\
* \text { Obj/NHum/Spec \& MAX-C }
\end{array}\right\} \gg *[+ \text { gov }] \gg * \text { Obj/NHum/NSpec \& MAX-C }
\end{aligned}
$$


For all types of objects except non-human, non-specific ones the faithfulness constraint MAX-CASE outranks the markedness constraint *[+gov]. [+gov] is thus retained on these objects. In the case of highly canonical (i. e., non-human, non-specific) objects, on the other hand, the markedness constraint outranks the faithfulness constraint, yielding impoverishment of [+gov]. This constraint ranking hence has essentially the same effect as the impoverishment rule in (6-c) above: Deletion of [+gov] in the case of non-human, non-specific objects. However, it is far more restrictive: While nothing prevents an impoverishment rule to solely apply to specific, human objects (yielding an 'anti-hierarchy effect'), this is impossible under the present approach. Impoverishment of specific, human objects is possible only if $*[+$ gov $]$ outranks the faithfulness constraint for specific, human objects. Given the inherent ranking in (13), it must then by transitivity be ranked higher than all other faithfulness constraints, leading to impoverishment for these objects as well. Harmonic alignment of scales thus restricts impoverishment in the following way: If deletion applies to a given argument, it must also apply to all less marked arguments, since the ranking of faithfulness constraints corresponds to hierarchical markedness.

The interaction between faithfulness and markedness constraints is illustrated in (15) and (16). Here, the input for optimization is the output of syntax; and the optimal output is the input for morphological realization.

\begin{tabular}{|c|c|c|c|c|c|}
\hline $\begin{array}{l}\text { Input: } \\
{[\text { obj,-hum,-spec][+gov] }}\end{array}$ & $\begin{array}{l}*_{0} \mathrm{o} / \mathrm{+h} /+\mathrm{s} \\
\& \text { MAX-C }\end{array}$ & $\begin{array}{c}*^{*} \mathrm{o} / \mathrm{+h} /-\mathrm{s} \\
\& \mathrm{MAX}-\mathrm{C}\end{array}$ & $\begin{array}{l}*_{\mathrm{o} /-\mathrm{h} /+\mathrm{s}} \\
\& \text { MAX-C }\end{array}$ & $*[+$ gov $]$ & $\begin{array}{c}*^{*} \mathrm{O} /-\mathrm{h} /-\mathrm{s} \\
\& \mathrm{MAX}-\mathrm{C}\end{array}$ \\
\hline D国 $[$ obj,-hum,-spec] & & & & & * \\
\hline $\begin{array}{l}{[\text { obj,-hum,-spec }]} \\
{[+ \text { gov }]}\end{array}$ & & & & $* !$ & \\
\hline \multicolumn{6}{|l|}{ Tableau for (4-b) } \\
\hline $\begin{array}{l}\text { Input: } \\
{[\mathrm{obj},- \text { hum,+spec][+gov] }}\end{array}$ & $\begin{array}{l}{ }^{*} \mathrm{o} /+\mathrm{h} /+\mathrm{s} \\
\& \mathrm{MAX}-\mathrm{C}\end{array}$ & $\begin{array}{l}{ }^{*} \mathrm{o} /+\mathrm{h} /-\mathrm{S} \\
\& \mathrm{MAX}-\mathrm{C}\end{array}$ & $\begin{array}{l}*^{*} \mathrm{O} /-\mathrm{h} /+\mathrm{S} \\
\& \mathrm{MAX}-\mathrm{C}\end{array}$ & $*[+\mathrm{gov}]$ & $\begin{array}{l}*_{\mathrm{o} /-\mathrm{h} /-\mathrm{S}} \\
\& \mathrm{MAX}-\mathrm{C}\end{array}$ \\
\hline [obj,-hum,+spec] & & & *! & & \\
\hline $\begin{array}{l}{[\text { obj,-hum,+spec }]} \\
{[+ \text { gov }]}\end{array}$ & & & & $*$ & \\
\hline
\end{tabular}

Given the markers in (6), everything proceeds as usual now: The winner of (15) can only be attached the zero marker since $-k o$ does not fulfill the Subset principle. The winner in (16), by contrast, is attached $-k o$ as $-k o$ is more specific than the zero marker. Hence, only highly canonical objects are zero marked, all others bear $-k o$.

\subsection{Differential Encoding of Objects in Mannheim German}

Since Hindi object marking instantiates a zero/non-zero alternation, it can equally well be captured in Aissen's (1999; 2003) system. In this section, we consider a non-zero/non-zero alternation in Mannheim German that is subject to identical principles as seen in Hindi. This suggests a unified approach, which, however, is not available if a theory can only account for zero/non-zero alternations.

In the variety of German spoken in and around Mannheim, non-pronominal masculine DPs are indistinguishable in nominative and accusative environments, as shown in (17) (so-called "Rheinischer Akkusativ"; see Behaghel (1911), Karch (1975), Müller (2003), and references cited there). Crucially, this does not hold for personal pronouns, cf. (18). 


\section{Case marking of non-pronominal objects}

a. Ich wünsch Ihnen [NP ein- $\varnothing$ schön-er Tag ] noch I wish you $_{d a t}$ a-NOM nice-NOM day PRT

b. Hol mir mal [NP der Eimer ] fetch me PRT the-NOM bucket

Case marking of pronominal objects

$$
\begin{array}{llllll}
\text { Hol en } & / & * \text { er } & \text { mir } & \text { mal } & \text { her } \\
\text { fetch he-ACC } & / & \text { he-NOM } & \text { me-DAT } & \text { PRT } & \text { PRT }
\end{array}
$$

This distribution correlates with the predictions of the definiteness scale in (2), suggesting an approach in terms of scales. Importantly, the alternation at hand is between two overt markers, i. e. $-n$ and $-r$. The present system accounts for this alternation in an analoguous way to Hindi above. Consider case and gender/number decomposition as in (19) (Wiese (1999); alternatives are Blevins (1995) and Wunderlich (1997))

$$
\begin{array}{llll}
\text { NOM: } & {[- \text { obl, }, \text { gov }]} & \text { MASC: } & {[+ \text { masc },- \text { fem }]} \\
\text { ACC: } & {[- \text { obl,+gov }]} & \text { FEM: } & {[- \text { masc },+ \text { fem }]} \\
\text { DAT: } & {[+ \text { obl, +gov }]} & \text { NEUT: } & {[+ \text { masc },+ \text { fem }]} \\
\text { GEN: } & {[+ \text { obl },- \text { gov }]} & \text { PL: } & {[- \text { masc },- \text { fem }]}
\end{array}
$$

The two markers under consideration are specified as in (20). They conform to iconicity because the more specific marker $-n$ is more marked in terms of sonority. This also correlates with their distribution: $-n$ marks only objects, whereas $-r$ can be attached to subjects and objects.

$$
\text { Vocabulary items: } \quad \begin{aligned}
/-\mathrm{n} / & \leftrightarrow[+ \text { masc, }+ \text { gov }] \\
/-\mathrm{r} / & \leftrightarrow[+ \text { masc }]
\end{aligned}
$$

Since the marker alternation under consideration regards pronominal vs. non-pronominal objects, the GF and Definiteness scales are relevant here.
a. GF scale
Subject $>$ Object
b. Definiteness scale
Pro(noun) $>$ Proper noun $(\mathrm{PN})>\operatorname{Def}($ inite $)>$ Indefinite Specific $($ Spec $)>$ NonSpecific (NSpec)

Harmonic alignment just as in Hindi above results in the constraint alignment in (22).

$$
* \text { Obj/Pro } \gg * \text { Obj/PN } \gg * O b j / \text { Def } \gg * O b j / S p e c ~ \gg * O b j / N S p e c
$$

Again corresponding to Hindi, these constraints are locally conjoined with the faitfulness constraint MAX-CASE. The markedness constraint * $[+$ gov $]$ is then inserted into this ranking as in (23).

$$
* \text { Obj/Pro \& MAX-C } \gg *[+ \text { gov }] \gg\left\{\begin{array}{l}
* \text { Obj/PN \& MAX-C } \\
* \text { Obj/Def \& MAX-C } \\
* \text { Obj/Spec \& MAX-C } \\
* \text { Obj/NSpec \& MAX-C }
\end{array}\right\}
$$


This ranking has the effect that [+gov] is retained for pronominal objects (since for these MAX-CASE outranks *[+gov] while it is deleted for all other types of objects). Consequently, pronominal objects are marked with $-n$, whereas all other objects bear the more general marker $-r$.

We thus conclude that the organizing principles of object marking in Hindi and Mannheim German are identical-markedness scales. Canonical objects bear a 'smaller' marker than non-canonical ones. The account proposed in Aissen (1999, 2003), however, is unable to capture this correspondence since it only derives zero/non-zero alternations, thus falling short of the Mannheim facts. This account therefore forces one to treat both alternations as unrelated, clearly missing a generalization. The impoverishment account proposed here offers a unified analysis for both Hindi and Mannheim German. Zero/nonzero alternations are thus only a proper subcase of more/less alternations and theories of differential case marking should not be restricted to this subcase.

\subsection{Trumai}

Recall that in the present proposal markedness constraints against case features do not simply penalize the presence of just any case feature. Instead, they are relatived to certain subfeatures. As seen above, this derives alternations between two overt markers. In addition, several markedness constraints can be inserted into distinct positions, thereby outranking a different set of faithfulness constraints. Impoverishment then proceeds in several steps, giving rise to alternation between more than two markers. Object marking in Trumai instantiates such a system and thus provides further evidence for the present proposal.

Trumai, a language isolate spoken in central Brazil by 51 speakers, has three dative markers $-(V) t l$, $-k i$, and $-(V) s$ (Guirardello (1999)). The choice among them is conditioned by the factors individuation and prominence, as shown in (24). Some examples are provided in (25)-(26)

Distribution of dative markers in Trumai (Guirardello $(1999,280)$ )

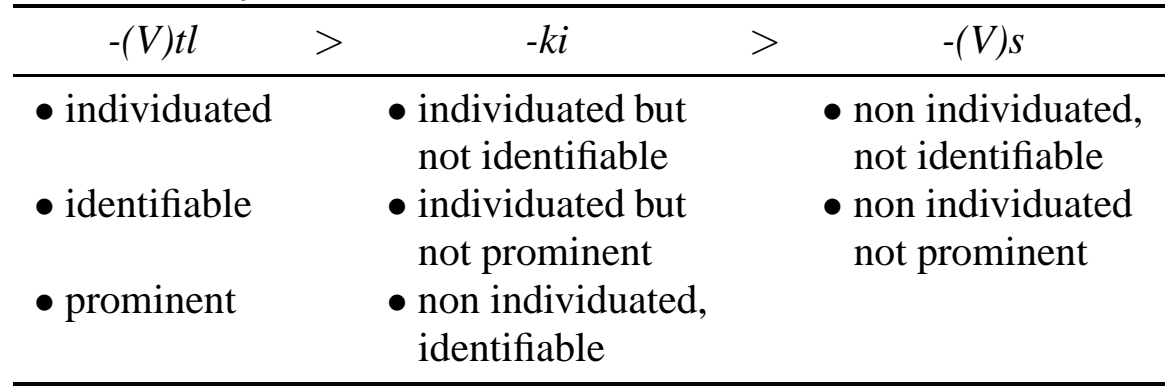
a. ha hu'tsa chï_in kasoro-tl
I see Foc/Tens dog-DAT
'I saw the dog (I know it).'
b. ha hu'tsa chï_in kasoro yi-ki
I see Foc/Tens dog YI-DAT
'I saw a dog/the dog (I do not know it well).'
c. ha hu'tsa chï_in kasoro-s
I see Foc/Tens dog-DAT
'I saw dogs.'

(Guirardello (1999, 276)) 

a. hi fa-tke-a
hai-tl?
I kill/hit-DES-QUEST 1-DAT
'Do you want to kill me?'

b. ha fa fa chï_in ine-tl

I kill/hit kill/hit FOC/TENS 3-DAT

'I beat him (someone that I know well).'
c. ha fa fa chï_in ine yi-ki
I kill/hit kill/hit FOC/TENS 3 YI-DAT
'I beat him (somebody that I do not know; he is a stranger).'

(ibid, 271)

(ibid, 272)

The distribution of the three markers in terms of markedness scales corresponds to their phonological markedness: $-(V) t l$ is most marked both for distribution and phonological complexity, followed by $-k i ;-(V) s$ is the least marked among the three. This correspondence can be straightforwardly derived within the present system as follows.

Assume the scales in (27). Harmonic alignment, conversion into a constraint ranking and local conjunction with the constraint MAX-C leads to the ranking in (28).
a. Individuation scale
Ind(ividuated) $>$ Non-ind(ividuated)
b. Prominence scale
$\mathrm{X}>\mathrm{x}$ (discourse-prominent argument $>$ non-discourse prominent argument)
c. GF scale
Subject $>$ Object
a. ${ }^{*} \mathrm{Obj} / \mathrm{Ind} / \mathrm{X} \& \mathrm{MAX}-\mathrm{C} \gg * \mathrm{Obj} / \mathrm{Ind} / \mathrm{x} \& \mathrm{MAX}-\mathrm{C}$
b. *Obj/Non-ind/X \& MAX-C $\gg * O b j / N o n-i n d / x ~ \& ~ M A X-C$

Analysing the dative as consisting of the subfeatures in (29), the three dative markers can be considered as being specified as in (30). Note that all three markers conform to iconicity.

$$
\begin{aligned}
& \text { DATIVE: [+obl, -subj, +gov] } \\
& \text { /-(V)tll } \leftrightarrow[\text { [+obl, -subj, +gov }] \\
& \text { /-(V)s/ } \leftrightarrow[- \text { subj] }
\end{aligned}
$$

Since markedness constraints are only sensitive to the presence of a certain case subfeature, two such constraints can be inserted into different positions within the ranking. This yields the three-way alternation of the dative. Here we assume the constraints $*[+o b l]$ and $*[+$ gov $]$. Consider the ranking in (31).

$$
\begin{aligned}
& * \text { Obj/Ind/X \& MAX-C } \gg[+ \text { obl }] \\
& \gg\left\{\begin{array}{l}
* \text { Obj/Ind/x \& MAX-C } \\
* \text { Obj/Non-ind/X \& MAX-C }
\end{array}\right\} \gg *[+ \text { gov }] \\
& \gg * \text { Obj/Non-ind/x \& MAX-C }
\end{aligned}
$$

This ranking has the effect that highly marked objects are not impoverished at all. For more canonical objects, [+obl] is deleted, but only highly canonical objects additionally have their [+gov] deleted. Due to iconicity, every impoverishment step is associated with insertion of a phonologically less marked exponent. This yields the pattern in (25) and (26): 
Prominent and individuated objects bear $-(V) t l$, less marked objects are marked with $-k i$, and non-prominent, non-individuated objects - the least marked object type-bear - $(V) s$.

In contrast, Aissen's approach is silent on the Trumai data as it does not involve a zero/non-zero alternation. That the principles at work here are the same as in the cases considered by her cannot be accounted for. The present approach, on the other hand, derives these alternations along the same lines and therefore captures their striking similarity.

\subsection{Cavineña}

The final system to be considered here is object marking in Cavineña, a Tacanan language spoken in Bolivia by less than 1,200 speakers (Guillaume (2008)). There are two overt dative/genitive markers: $-k w e$ and $-j a$. Their choice is conditioned by person and number of the stem: Highly non-canonical objects-local person and singular-bear - kwe. All other combinations select $-j a$. This distribution correlates with the phonological complexity of the two markers: - $k w e$ is more marked phonologically than -ja. Hierarchical markedness thus corresponds to mophological markedness. This instantiates a more/less alternation in differential object marking. The distribution of the two markers is given in (32), along with some examples in (33). ${ }^{3}$

\begin{tabular}{llll}
\multicolumn{4}{l}{ Distribution of markers } \\
\hline Person/Number & \multicolumn{1}{c}{ SG } & \multicolumn{1}{c}{ DL } & \multicolumn{1}{c}{ PL } \\
\hline 1 & e- $\varnothing-k w e$ & ya-tse-ja & e-kwana-ja \\
2 & mi- $\varnothing-k w e$ & me-tse-ja & mi-kwana-ja \\
3 & tu- $\emptyset-j a$ & ta-tse-ja & tu-na-ja \\
3PROX & riya- $\varnothing-j a$ & re-tse-ja & re-na-ja \\
\hline
\end{tabular}
a. E-kwe ani-kware [ maletero ari- $\left.\mathrm{da}_{C C}=\mathrm{ke}_{R C}\right]_{S}$ 1SG-DAT sit-REM.PAST bag big-ASF=LIG 'I had a big bag (lit. a big bag sat to me).'
b. Sergio=ja ani-ya [ata Ramón bakani $]_{S}$
Sergio=DAT sit-IMPFV relative Ramsón name
'Sergio had a relative called Ramón (lit. a relative called Ramón was sitting to Sergio).'
c. $\quad$ Tume $=$ tuna-ja $=$ tu-ke $=\emptyset_{A} \quad$ be-ti-wa budari $O$
then $=3$ PL-DAT $=3$ SG-FM (=1SG.ERG) bring-GO.TEMP-PERF banana
'I will go and bring bananas for them.'
(Guillaume $(2008,567))$

Since the distribution of these two markers depends on person and number, the person and number scale, along with the GF scale, are relevant for Cavineña.

$$
\begin{aligned}
\text { a. } & \text { Person scale } \\
\text { b. } & \text { Loc }(\text { al })(1 / 2)>\mathrm{N}(\text { on }) \operatorname{loc}(\mathrm{al}) \\
& \text { Number scale } \\
& \mathrm{Sg}>\text { Non-sg }
\end{aligned}
$$

3 The following abbreviations are used in the glosses: ASF: adjective suffix; CC: copula complement; FM: formative; LIG: ligature; O: transitive object; RC: relative clause; S: intransitive subject; TEMP: temporarily. 


$$
\begin{array}{ll}
\text { c. } & \text { GF scale } \\
\text { Subj }>\text { Obj }
\end{array}
$$

Harmonic alignment, conversion into a constraint ranking and subsequent conjunction with MAX-C leads to the ranking of faithfulness constraints in (35).

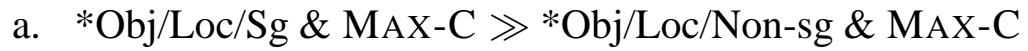

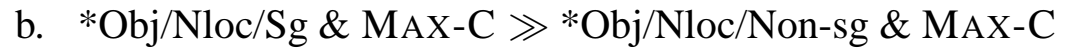

We assume that the dative comprises the subfeatures in (36). The markers - $k w e$ and $-j a$ are analysed as in (37), obeying iconicity.

$$
\begin{aligned}
& \text { DAtive: }[+ \text { obl, }+ \text { obj }] \\
& \text { /-kwe/ } \leftrightarrow[+o b l,+o b j]
\end{aligned}
$$

The markedness constraint $*[+o b l]$ is then inserted into the ranking of faithfulness constraints, cf. (38). This ranking yields to deletion of [+obl] for all except highly marked objects (local person, singular) because only the for this type of object does the faithfulness constraint outrank the markedness constraint. Given the markers as specified in (37), deletion of [+obl] bleeds insertion of $-k w e$ and thus leads to a retreat to the more general marker $-j a$.

$$
* \text { Obj/Loc/Sg \& MAX-C } \gg *[+o b l] \gg\left\{\begin{array}{l}
* \text { Obj/Loc/Non-sg \& MAX-C } \\
* \text { Obj/Nloc/Sg \& MAX-C } \\
* \text { Obj/Nloc/Non-sg \& MAX-C }
\end{array}\right\}
$$

Notably, apart from being more restrictive, the constraint ranking in (38) has another advantage over an explicit impoverishment rule with the same effect: Impoverishment applies if the object is non-local or non-singular. As these contexts arguably do not form a natural class, the impoverishment rule at hand would have to involve a disjunction. If, on the other hand, the context in which impoverishment takes place is derived by harmonic alignment of scales as in the present approach, the case feature is deleted in all environments that are dominated by the markedness constraint $*[+o b l]$. (38) shows that this comprises exactly the domain of objects that are non-singular or non-local. What these contexts have in common, then, is that they form a homogenuous section of a constraint ranking: They are less marked than a certain cut-off point established by the insertion of the markedness constraint *[+obl]. The approach developed here is therefore superior on conceptual grounds.

The Cavineña data clearly conform to what is expected from the point of view of Hale/Silverstein hierarchies-more marking for unexpected objects. These data are nevertheless surprising if scales can only lead to a total reduction in morphological marking.

\section{Summary}

Based on the empirical observation that differential argument encoding is not restricted to zero/non-zero alternations but might also involve two or more overt markers, we have developed an approach that crucially relies on impoverishment. ${ }^{4}$ Under the perspective

\footnotetext{
4 For an application to a wider range of marking systems including Finnish see Keine and Müller (2008).
} 


\section{Non-Zero/Non-Zero Alternations in Differential Object Marking}

pursued here, impoverishment is brought about by high-ranked markedness constraints in an OT-style syntax-morphology mapping (much as in Pesetsky (1998)). The scale effects are implemented by means of harmonic alignment of scales and local conjunction. Since both operations by definition impose restrictions on the resulting constraint ranking, they also impose restrictions on impoverishment. Specifically, if impoverishment applies to a certain type of argument it also applies to all less marked types. Consequently, then, impoverishment is functionally motivated and constrained.

\section{Bibliography}

Aissen, Judith (1999): 'Markedness and Subject Choice in Optimality Theory', Natural Language and Linguistic Theory 17, 673-711.

Aissen, Judith (2003): 'Differential Object Marking: Iconicity vs. Economy', Natural Language and Linguistic Theory 21, 435-483.

Anand, Pranav and Andrew Nevins (2006): The Locus of Ergative Case Assignment: Evidence from Scope. In: A. Johns, D. Massam and J. Ndayiragije, eds, Ergativity. Springer, pp. 3-25.

Behaghel, Otto (1911): Geschichte der deutschen Sprache. Trübner, Straßburg.

Bickel, Balthasar (2007): How Good is the Evidence for Referential Scales?. Ms., Universität Leipzig.

Bickel, Balthasar and Alena Witzlack-Makarevich (2008): Referential Scales and Alignment: A Critical Review of the Typological Evidence. Ms., Universtität Leipzig.

Blevins, James (1995): 'Syncretism and Paradigmatic Opposition', Linguistics and Philosophy 18, 113-152.

Bonet, Eulália (1991): Morphology after Syntax. PhD thesis, MIT, Cambridge, Mass.

Brown, Jason, Karsten Koch and Martina Wiltschko (2004): The Person Hierarchy: Primitive or Epiphenomenal? Evidence from Halkomelem Salish. Ms., University of British Columbia. To appear in Proceedings of NELS 34.

Butt, Miriam and Tracy King (2004): The Status of Case. In: V. Dayal and A. Mahajan, eds, Clause Structure in South Asian Languages. Kluwer, Boston, pp. 153-198.

Carnie, Andrew (2005): 'Some Remarks on Markedness Hierarchies', Coyote Working Papers in Linguistics 14.

Guillaume, Antoine (2008): A Grammar of Cavineña. Mouton de Gruyter, Berlin.

Guirardello, Raquel (1999): A Reference Grammar of Trumai. PhD thesis, Rice University, Houston, Texas.

Hale, Ken (1972): A New Perspective on American Indian Linguistics. In: A. Ortiz, ed., New Perspectives on the Pueblos. University of New Mexico Press, Albuquerque, pp. 87-103.

Halle, Morris and Alec Marantz (1993): Distributed Morphology and the Pieces of Inflection. In: K. Hale and S. J. Keyser, eds, The View from Building 20. MIT Press, Cambridge, Mass., pp. 111-176.

Halle, Morris and Alec Marantz (1994): Some Key Features of Distributed Morphology. In: A. Carnie, H. Harley and T. Bures, eds, Papers on Phonology and Morphology. Vol. 21 of MIT Working Papers in Linguistics, MITWPL, Cambridge, Mass., pp. $275-288$. 
Harbour, Daniel (2008): The Syntactic Basis of Phi-Case Interaction. Ms., Queen Mary College, University of London.

Haspelmath, Martin (2007): Prominence Scales in Differential Object Marking: A Critique of Aissen (2003). Ms., MPI-EVA, Leipzig.

Karch, Dieter (1975): Zur Morphologie vorderpfälzischer Dialekte. Niemeyer.

Keine, Stefan (2007): Reanalysing Hindi Split Ergativity as a Morphological Phenomenon. In: J. Trommer and A. Opitz, eds, 12 Many. Vol. 85 of Linguistische Arbeitsberichte, Universität Leipzig, pp. 73-127.

Keine, Stefan and Gereon Müller (2008): Differential Argument Encoding by Impoverishment. In: M. Richards and A. Malchukov, eds, Scales. Vol. 86 of Linguistische Arbeitsberichte, Universität Leipzig, pp. 83-136.

Lumsden, John (1992): 'Underspecification in Grammatical and Natural Gender', Linguistic Inquiry 23, 469-486.

Mahajan, Anoop (1990): The A/A-bar Distinction and Movement Theory. PhD thesis, MIT, Cambridge, Mass.

Mohanan, Tara (1994): Argument Structure in Hindi. CSLI Publications, Stanford.

Müller, Gereon (2003): 'Zwei Theorien der pronominalen Flexion im Deutschen (Versionen Standard und Mannheim)', Deutsche Sprache 30, 328-363.

Ortmann, Albert (2002): Economy-Based Splits, Constraints and Lexical Representations. In: I. Kaufmann and B. Stiebels, eds, More than Words: A Festschrift for Dieter Wunderlich. Akademie Verlag, Berlin, pp. 147-177.

Pesetsky, David (1998): Some Optimality Principles of Sentence Pronunciation. In: P. Barbosa, D. Fox, P. Hagstrom, M. McGinnis and D. Pesetsky, eds, Is the Best Good Enough?. MIT Press and MITWPL, Cambridge, Mass., pp. 337-383.

Prince, Alan and Paul Smolensky (2004): Optimality Theory. Constraint Interaction in Generative Grammar. Blackwell, Oxford.

Richards, Marc (2008): Defective Agree, Case Alternations, and the Prominence of Person. In: M. Richards and A. Malchukov, eds, Scales. Vol. 86 of Linguistische Arbeitsberichte, Universität Leipzig, pp. 137-161.

Silverstein, Michael (1976): Hierarchy of Features and Ergativity. In: R. Dixon, ed., Grammatical Categories in Australian Languages. Australian Institute of Aboriginal Studies, Canberra, pp. 112-171.

Stiebels, Barbara (2002): Typologie des Argumentlinkings: Ökonomie und Expressivität. Akademie Verlag, Berlin.

Trommer, Jochen (2006): Head-Level and Chain-Level Constraints on Spellout. In: J. Costa and M. C. F. Silva, eds, Studies on Agreement. Benjamins, Amsterdam.

Wiese, Bernd (1999): 'Unterspezifizierte Paradigmen. Form und Funktion in der pronominalen Deklination', Linguistik Online 4. (www.linguistik-online.de/3_99).

Wiese, Bernd (2004): Categories and Paradigms: On Underspecification in Russian Declension. In: G. Müller, L. Gunkel and G. Zifonun, eds, Explorations in Nominal Inflection. Mouton de Gruyter, Berlin, pp. 321-372.

Woolford, Ellen (2001): Case Patterns. In: G. Legendre, J. Grimshaw and S. Vikner, eds, Optimality-Theoretic Syntax. MIT Press, Cambridge, Mass., pp. 509-543.

Wunderlich, Dieter (1997): Der unterspezifizierte Artikel. In: C. Dürscheid, K. H. Ramers and M. Schwarz, eds, Sprache im Fokus. Niemeyer, Tübingen, pp. 47-55. 